\title{
Housing for all: analysis of possibility and potential
}

\author{
Darpagiri Mondal and Bishwajit Bhattacharjee*
}

Housing affordability in India was analysed on the basis of house hold expenditure data. The data available in the Census reports of 2011-12, Levels and Patterns of Household Consumer Expenditure was considered for this study. Curve for cumulative population distribution against monthly per-capita expenditure (MPCE) was obtained and equations were fitted to obtain mathematical relationships. Parameters of distributions were presented for all the states and Union Territories on rural and urban basis. Poverty line basket (PLB) was considered along with MPCE to relate the percentage of population having housing affordability on an all India perspective. The affordable estimated monthly installment (EMI) and the corresponding fraction of population as potential market, was worked out through developed equations, for MPCE values up to the level, where supply exceeded the demand of housing. Construction cost was considered for feasibility of affording a house and it was explained that industrialized building construction might provide the suitability of realizing the market.

Keywords: Housing, industrialized building construction, per-capita expenditure, poverty line basket.

HoUSING shortage, both in urban and rural sectors, has been recognized by many studies ${ }^{1,2}$. This shortage is also recognized by Government of India (GoI) and thus, launched the 'Pradhan Mantri Awas Yojana-2015' (PMAY), that envisages providing housing to all citizens by 2022 with an emphasis on affordable housing. According to the census of India 2011, 86.6\% of families on a national average own a house, with the state of Bihar, at the top with $96.8 \%$ and Union Territory (UT) of Daman and Diu at the bottom at $38.3 \%$ (ref. 3). The remaining $13.4 \%$ is quite large in absolute terms (170-180 million). Other literature indicate that almost 1.94 million people in India are still house-less ${ }^{4,5}$. Thus by any count, there is a huge housing shortage in India. Interestingly, out of the total 330.84 million houses in the country, 24.67 million houses are still lying vacant. Also, the housing shortage currently being faced is mostly by the economically weaker section (EWS) and lower income group (LIG) category of the population, with EWS group accounting for $56 \%$ of this category facing shortage, as indicated in some of the earlier literature. These numbers indicate that merely constructing houses is not enough, but the constructed houses should be 'affordable' to the intended target population, otherwise would remain 'vacant' without reducing 'housing shortage'. A distinction is made

Darpagiri Mondal is at the Indian School of Business and Bishwajit Bhattacharjee is in the Department of Civil Engineering, Indian Institute of Technology Delhi, New Delhi 110 016, India.

*For correspondence. (e-mail: bishwa@civil.iitd.ac.in) here between any space where people manage to live and a habitable house. The lowest level of a habitable house is just hygienic, at tolerable limits with regard to thermal, visual comforts, etc. but safe against all forms of structural loads.

The area is just sufficient from ergonomics point of view with adequate circulation for habitable space ${ }^{6}$. Thus, an affordable house considered in this paper is at this lowest level of acceptability and corresponds to the house that is often designated as housing for EWS.

\section{Housing affordability}

'Housing affordability' has been defined as the ability to purchase and retain an adequate amount of habitable space with access to basic amenities, also, developing a relationship between the house and people living in $\mathrm{it}^{7,8}$. The earliest concept of affordability reported was a measure that was used by landlords while looking for tenants. The most popular notion was: 'one week's pay for one month's rent'. This effective ratio of housing expenditure to income works out to be nearly 0.25 . Researchers as early as 1912 (ref. 9), noticed trends of housing expenditure as compared to income. According to Kengott's research the ratio was around $20 \%$. Other researchers like Hulchanski ${ }^{10}$, Houthaker ${ }^{11}$ and Stigler ${ }^{12}$ have all worked on household costs to income ratios. Hulchanski ${ }^{10}$ further stated that, Engel proposed certain 'laws' relating to the proportion of income spent on food 
and rent with variation in household incomes. These laws are strictly based on ratios, and considered averages, as they are very easy to use and understand. Gan and Hill ${ }^{13}$ used median measures to quantify affordability, as the population distributions are vast and often skewed, which means that the average measure may not give the whole picture. They used a simple model to judge whether a house would be affordable to a household having a specific income, and also used time-value of money. Also, they took into account affordability being at 'risk'. This would give the proportion of houses which would put the household at risk, if it were to purchase it. They emphasized looking at the entire distribution instead of just the median or average values.

Mulliner et $a l .{ }^{14}$, measured housing affordability using multiple criteria decision making methods. They focused on other factors which played a role in making certain houses more affordable than others, like - housing quality, location and neighbourhood characteristics, etc. Their research selected 20 criteria and weighed them to assess affordability in a more comprehensive manner rather than simply looking at income to expenditure ratios. More recently, Demographia Internationalia ${ }^{15}$ an organization which conducted housing affordability surveys in nine developed countries, showed trends of changing housing affordability in these countries. Median multiple is the ratio of median annual income of a household to the median of price of a house. A value of 5.1 and above represents high unaffordability while 3.0 and lower represents affordability. The median-multiple shows good correlation with the actual housing markets in these countries over time. However, the case of a developing country like India is likely to be different than the measure considered by the earlier researchers.

Stone ${ }^{8}$ and Kutty $^{16}$ defined affordability based on a concept of 'residual income' and these researchers talked about a 'basket' of goods which included all basic necessities required by a household, called as 'poverty basket'. Accordingly, any household which is not capable of purchasing this 'basket' of goods after paying for their house has an affordability problem. Thus the standard of living and spending have a bearing on retaining and maintaining the house. Kutty ${ }^{16}$ based her research in the United States and used the official poverty line to arrive at the poverty line basket (PLB). She set the value of being able to afford a poverty basket of non-housing goods at an expenditure of $2 / 3$ rds of the poverty line established by the US government. Hence for realization of 'housing for all' it is necessary that the expenditure capacity of a household for all household under consideration shall be at least $(1+0.67) /(1-0.25)=2.23$ times the poverty line basket $(2.23 \times \mathrm{PLB})$. Thus housing affordability is related to PLB. An attempt is made to use PLB in India and relate them to an affordability measure, in order to analyse the possibility and potential of 'housing for all'.
Sources of Indian literature on housing affordability studies are relatively scarce. Affordability in India is also measured primarily as a ratio or percentage of household income. The basic minimum housing requirements for the EWS and LIG categories are specified in literature. It shall be understood that housing affordability does not solely imply the ability to purchase a house, but it also includes the ability to pay for taxes, utilities and maintenance costs during entire life. Unfortunately, there has not been much work done in this regard. Quantitative volume of affordable housing market is not reported in any literature as seen from available data so far. This paper provides simple relationships for quantitative volume of affordable housing in India as a whole, and also state wise for the first time in a unique manner by considering expenditure capability and upper limit of market for EWS housing. The analysis is based on published census data, thus realistic and practical. Private builders can take advantage of the proposed quantified volume for their initiatives in this segment of housing, and the state and planners can also take advantage of the same to enhance expenditure capacity of population and hence the possibility of housing for all.

\section{Factors affecting housing affordability}

Most of the affordability studies done in India have focused on the concept of affordability under the current situation in the country as perceived by developers, and the challenges faced by them in entering the affordable housing market ${ }^{2,17}$. There are many notable companies which are in this particular segment of housing, and with the current impetus being provided by the government, this segment is expected to see considerable growth. Research by some of these real estate companies shows that the current developers have conventionally catered to high and premium segments of housing rather than EWS and LIG segments. This is primarily because of the scale of returns achieved in these constructions. The demand for these types of houses is very low as compared to the demand for low cost or EWS housing. For example, demand at the lowest income level is $35 \%$ of total demand, while that for highest income segments, it is 5\%. Likewise, supply for the highest income segment is $30 \%$, resulting in high surplus availability at the higher income band. The volume of the market in the lower end of affordability is thus very high, provided this can be exploited with appropriate advanced technology, industrial mass production and proper planning. Thus cost reduction through adoption of appropriate construction technology is a factor for enhancing the possibility of housing for all.

Planning is important as improper infrastructure or lack of livelihood to the target population also makes a huge difference to the occupancy of such houses. For example, 
West Bengal government's relocation effort for slum dwellers faced a setback when they refused to move into their new apartments, as they lacked provisions for housing their poultry and livestock. Researchers mentioned 'live-ability' as one of the criteria to consider while constructing affordable housing ${ }^{18}$. The concept of ' $\mathrm{H}+\mathrm{T}$ ' affordability (or 'location affordability, that is related to travel') was also discussed in certain independent reports which merged together the cost of housing and transportation to place of work. According to this concept, the location far away from work 'adds' to the cost borne by an individual and can potentially make the house 'unaffordable'.

Apart from the fact that affordable housing needs to be able to suit the economic capacity of the target population, extensive literature also suggests that, various other factors may also lead to the success or failure of a housing project, especially in rural areas ${ }^{19,20}$. One of the major reasons identified by the literature is social community belonging to the area. If people and families do not have a sense of belonging to that area, they may not even tend to live in that area. Apart from this, there are reasons like - distance to place of work, sources of livelihood, insufficient or inappropriate infrastructure, this sense of non-belongingness linked to their way of life, the customs and their day-to-day living. For example, houses in certain areas of the country absolutely need some sort of a small courtyard. While this may be difficult to provide in an urban area, it can be provided in rural areas with careful planning and design and even in cluster housing. Such efforts supposedly have been made under the Indira Awaas Yojana (IAY) scheme ${ }^{21}$.

Another reason which reportedly played an important role in many such community projects around the globe was use of traditional materials which were cheaper and socially acceptable ${ }^{20}$. The involvement of local people in construction would generate small time employment for them and the houses thus built, would be more acceptable to them. Reports of projects in China and Brazil have demonstrated that innovation in blending of modern techniques with local materials can make successful affordable houses. Further, in some cases, as the families grow in rural areas, and eventually when they become large, they tend to stay intact and individuals live together. For example, the Aranya community housing project in Indore $^{22}$, India, has handled this exceptionally well by making the design up-scalable, easy to build and using local materials. However, scales of these projects will be small, and cannot cater to 'Housing for all', in a country like India with an enormous housing requirement even in rural areas. Rate of construction with local materials and manual construction with unskilled people, will be slow. With durability of traditional materials being low, their renewal period will be short, rendering the life cycle cost of such construction systems high. Thus large scale success of such projects are not apparent ${ }^{23}$. Strength study of soil blocks of sizes similar to that used for cement testing exhibit compressive strength lower than $3 \mathrm{MPa}$, and that maximum for stabilized soil cement block was found to be of the order of $15 \mathrm{MPa}$ (refs 24, 25). Further, these issues of lower strength, constructability, rate of construction and maintenance frequency are considerably harder to tackle for construction with local materials both in rural and in urban areas.

As evident from the above sections, although project of the kind of IAY, etc. are launched from time to time to tackle the problem of housing for masses in India, and similarly, at present the idea of PMAY is floated yet again, the issue of providing housing to all, still remains unsolved. Success of such projects at national or at state levels depends on two main factors: (1) The expenditure capacity of people and consequent potential market likely to be generated. (2) The current sphere of construction materials and construction technology used. Role of these two factors on potential affordable housing volume are considered in the next section. The first factor is discussed in the beginning. The second factor is then discussed to rationalize the objectives identified for the analysis presented in this paper. Certain relatively less dominant factors, such as aspiration of population to possess consumer goods and amenities needed over and above those required beyond $2.23 \times$ PLB, are not considered as objectives to estimate the maximum possible available market for EWS house.

\section{Expenditure capacity, construction and volume of affordable housing}

To take account of expenditure capacity on volume of affordable housing, one can consider PLB that accounts for various livelihood requirements namely, food, durables, medical expenditure, education, rent and conveyance as the minimum and fundamental needs to be satisfied as first priority before owning a house. Houses made available to this section of population by state or similar agency without ensuring satisfaction of primary needs are likely to be sold, rented off, or disposed of, in some manner in order to purchase nutrition and other similar primary needs. Thus market for affordable housing lies above the PLB of expenditure, or more realistically above $2.23 \times$ PLB as illustrated earlier. PLB in the present study was obtained from National Sample Statistics Office (NSSO) census report ${ }^{26}$. The expenditure patterns of households in different states/UTs are also available from this census report ${ }^{26}$. The PLB values, for all-India rural and urban poverty lines, at that time, were set at Rs 973 and Rs 1407 per capita per month respectively $^{27}$. This points towards an interesting fact that the fraction of population below this level of monthly per capita expenditure cannot 'afford' a house at all, unless explicit avenues for enhanced expenditure capacity is 
ensured to this section by the state or otherwise, for their sustenance and surplus. Going by $2.23 \times$ PLB criteria, Rs 2170 and Rs 3138 are the affordability limits for housing (ALH) for rural and urban India. Under current state of their expenditure capacity, houses given to them, are likely to be disposed of in sale or at best on rent, rather than self-occupation, to trade-off for necessary expenditure on minimum calorie intakes, basic amenities and other more important primary needs. This is one of the major implications of these PLB values in the context of affordable housing. This also differentiates the government handled 'social housing' schemes or special 'low-cost housing' schemes from general affordable housing. Low-cost housing implies the houses specifically made for this particular section of population as they cannot afford a house on their own. Affordable housing would target the fraction of population which is capable of affording a house on their own, and only that section of the population is the focus of the present study. The present article thus attempts to provide a simple relationship between the populations capable of affording a house against the estimated monthly instalment (EMI).

Current domain of construction materials for building, spreads over a large range starting from lowest performing non/semi-engineered material such as rammed earth, adobe construction, to high performance concretes, steel, toughen glass and composites. Construction technology also ranges from manual construction by unskilled people to completely mechanized industrialized building construction with application of robotics and mechatronics. The manual construction with non-engineered material is labour intensive, has low initial cost but due to their higher renewal frequency and lower quality control, the life cycle cost for about 50 years of intended design life is high. Structurally these constructions also are restricted to low rise buildings. Usually, based on traditional practices of many years, functional design of a traditional house construction is climate responsive and socioculturally acceptable. But such construction cannot provide shelter for large population. Modern industrialized building construction on the other hand is capital intensive and requires high initial investment. Here, per unit cost of a house may become sufficiently low and affordable only beyond a break-even level of production. Quality control is better, both structural and functional design can be appropriate and pace of construction can be very high. This is the only feasible solution for achieving affordable housing for all in short span of time.

The maximum feasible number of housing units that can be fruitfully afforded by people in a given region corresponds to the population having an expenditure capacity greater than ALH and can afford an EMI of 25\% of monthly income. There is also an upper bound corresponding to surplus supply of houses over demand for a population having expenditure capability above a given amount. The cumulative expenditure distribution for
India as whole and state-wise distributions were obtained from the Census reports of 2011-12, Levels and Patterns of Household Consumer Expenditure ${ }^{26}$. The equation for best fit curve for these distributions is presented in this paper in the beginning. The feasible number is also a function of EMI, which is dependent on the capital cost of setting up of plant, machinery, etc. and cost of each unit of affordable housing. Since the capital cost is to be recovered over a reasonable period, overall selling price of unit would depend on number of feasible units. An expression for EMI is also presented and feasible number of housing is reported for overall Indian situation for two types of constructions and over likely residual deficit for future is highlighted.

\section{Expenditure capacity distribution and affordable housing market}

As per the census, the average size of a household is 4.9; taken as 5 in this article. Also, all the values of expenditure are expressed as monthly per-capita expenditure (MPCE), and will be referred to as MPCE hereafter. Combined all-India basis data of cumulative percentage of population against expenditure (MPCE) is shown in Figure 1. The points shown are obtained from a report ${ }^{26}$, and fitted smooth curve is obtained through curve fitting. The ratio of maximum to minimum of MPCE data is 10 or more, and such data range is more conveniently handled in $\log$ scale with a multiplying factor of 10 . Thus one can use $E=10 \times \log$ (MPCE) for convenience. The plot of cumulative percentage of population $P$ against expenditure $E$ is also shown in Figure 2. The best fit equation to these curves are obtained through regression (Chi-square minimization) is given below in eq. (1)

$$
P=\frac{a}{1+\left(\frac{b}{E}\right)^{c}},
$$

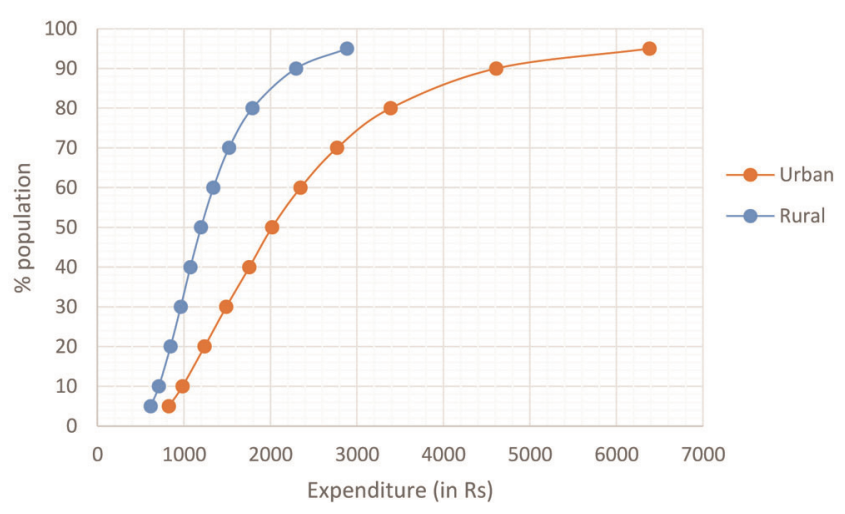

Figure 1. Cumulative \% of population against MPCE. 
where $P$ is the cumulative population in $\% ; a, b$ and $c$ constants obtained through regression and $E$ is the expenditure. Data from all the states, rural and urban fitted well in to this form of equation as indicated by their respective coefficients of determination. The coefficients of determination ranged from $90 \%$ to $99.9 \%$ in some cases. Equation (1) shows that for large $E$, the value tends to be 1 and $P$ asymptotically approaches its maximum value 100. Thus this leads to following: for $E \rightarrow \infty$, $P \rightarrow a=100$. Again for $b=E, P=50 \%$, thus $b$ is the median value of $E$ which equally divides the population, such that $50 \%$ population have higher and the rest $50 \%$ have lower expenditure capability corresponding to $E=b$. In eq. (1), the term $b / E$ varies around 1 , as, $b=E$ represents median. The function $P / 100$ ranges from 0 to 1 for some spread of $E$. Consider the first case, $b / E$ is less than 1, i.e. $E>b$ beyond median. For higher values of $c$, $P / 100$ will reach nearly 'unity' at lower value of $E$ with reference to $b$, as $b / E$ is a fraction, than that for lower values of $c$. When $b / E$ is greater than 1 , i.e. $E<b$ before median, similarly, at higher values of $c$, the function $P / 100$ will reach nearly zero at a lower value of $E$ away from $b$, than that for lower values of $c$. Thus higher $c$ means less spread and lower $c$ means higher spread of dispersion. Here $c$ indicates dispersion of distribution. The derivative $(\mathrm{d} P / \mathrm{d} E)$ is the density function, i.e. distribution of population per unit $E$

$$
P=\frac{\mathrm{d} P}{\mathrm{~d} E}=100\left[\frac{c b^{c}}{E^{c+1}\left(1+\left\{\frac{b}{E}\right\}^{c}\right)^{2}}\right] .
$$

Values of $b$ and $c$ for rural and urban population for all the states are given in Table 1 . The population percentage $\Delta P=p \Delta E$, corresponding to any small range of $\Delta E$ can be obtained from eq. (2). It can be shown that as $E \rightarrow 0$, $p \rightarrow 0$, and again as $E \rightarrow \infty, p \rightarrow 0$, as apparent in Figure 2 .

The PLB values for rural and urban India are Rs 973 and Rs 1407 per capita per month respectively, as mentioned earlier. Corresponding ALH values are Rs 2170

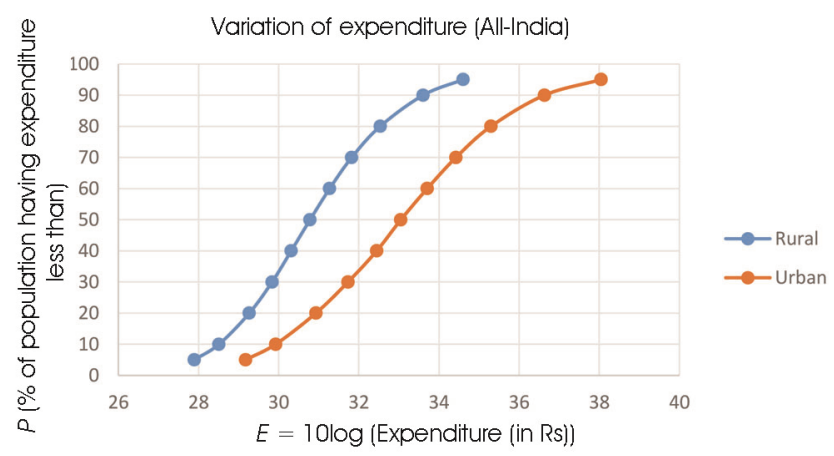

Figure 2. Cumulative $\%$ of population against $E$. and Rs 3138 and $E$ values are 33.4 and 35.0 for rural and urban India respectively. The all-India basis percentage of population which cannot afford a house other than where they are currently living, thus can be obtained from eq. (1) for both rural and urban cases. These population work out to be $89 \%$ and $77 \%$ respectively, for rural and urban India as a whole. Thus the maximum available market for housing would be $11 \%$ and $23 \%$ of rural and urban population as a whole. However there is surplus supply for higher income population ${ }^{28}$, which may correspond to monthly per capita expenditure capability of Rs 8500 , i.e. the family income per month for 5 member family household, as assumed, is Rs 42,500, leading to an annual family income of Rs 510,000. Accordingly 99.8\% of rural population have an income lower than that. Hence effective available housing market is nearly $11 \%$ of rural population. On the other hand, $97.5 \%$ of the urban population have income more than the amount specified above. Hence $23-2.5=20.5 \%$ of the population

Table 1. Constants $b$ and $c$ for different states in the country

\begin{tabular}{|c|c|c|c|c|}
\hline \multirow[b]{2}{*}{ States } & \multicolumn{2}{|c|}{ Rural } & \multicolumn{2}{|c|}{ Urban } \\
\hline & $b$ & $c$ & $b$ & $c$ \\
\hline All India & 30.82 & 26.57 & 33.07 & 21.34 \\
\hline Andhra Pradesh & 31.86 & 32.45 & 33.51 & 25.1 \\
\hline Arunachal & 31.42 & 19.99 & 33.16 & 18.68 \\
\hline Assam & 30.40 & 31.92 & 32.49 & 21.67 \\
\hline Bihar & 30.17 & 35.17 & 30.98 & 24.22 \\
\hline Chhattisgarh & 29.61 & 31.8 & 31.52 & 19.72 \\
\hline Delhi & 33.70 & 31.95 & 34.05 & 22.86 \\
\hline Goa & 33.27 & 32.27 & 34.21 & 25.89 \\
\hline Gujarat & 31.27 & 30.68 & 33.44 & 26.69 \\
\hline Haryana & 32.78 & 27.82 & 34.24 & 22.85 \\
\hline Himachal Pradesh & 32.33 & 28.95 & 34.44 & 21.21 \\
\hline Jammu \& Kashmir & 31.93 & 32.12 & 33.18 & 24.76 \\
\hline Jharkhand & 29.66 & 34.27 & 32.27 & 22.19 \\
\hline Karnataka & 31.24 & 32.2 & 33.39 & 19.56 \\
\hline Kerala & 33.02 & 24.83 & 33.75 & 21.8 \\
\hline Madhya Pradesh & 29.47 & 26.62 & 31.93 & 20.69 \\
\hline Maharashtra & 31.47 & 32.4 & 33.91 & 24.8 \\
\hline Manipur & 31.32 & 34.65 & 31.31 & 37.44 \\
\hline Meghalaya & 31.35 & 39.05 & 33.5 & 36.02 \\
\hline Mizoram & 31.67 & 28.71 & 33.73 & 30.35 \\
\hline Nagaland & 32.73 & 41.35 & 33.19 & 27.31 \\
\hline Odisha & 25.53 & 29.68 & 31.75 & 19.78 \\
\hline Punjab & 32.98 & 28.19 & 33.62 & 24.98 \\
\hline Rajasthan & 31.47 & 31.91 & 32.94 & 25.96 \\
\hline Sikkim & 31.46 & 40.9 & 33.73 & 35.8 \\
\hline Tamil Nadu & 31.62 & 26.69 & 33.25 & 23.86 \\
\hline Tripura & 30.81 & 32.5 & 32.54 & 23.69 \\
\hline Uttar Pradesh & 30.04 & 29.76 & 31.68 & 20.87 \\
\hline Uttarakhand & 31.75 & 31.3 & 32.89 & 23.23 \\
\hline West Bengal & 30.56 & 31.72 & 32.92 & 20.21 \\
\hline Andaman \& Nicobar & 33.49 & 29.95 & 35.54 & 30.26 \\
\hline Chandigarh & 33.33 & 27.3 & 34.0 & 19.12 \\
\hline Dadra \& Nagar Haveli & 29.89 & 26.62 & 33.34 & 29.8 \\
\hline Daman \& Diu & 33.08 & 29.14 & 33.36 & 36.11 \\
\hline Lakshadweep & 33.92 & 46.58 & 33.87 & 27.1 \\
\hline Puducherry & 32.95 & 32.39 & 34.33 & 28.46 \\
\hline
\end{tabular}


Table 2. EMI ranges, cost, potential market for rural India

\begin{tabular}{|c|c|c|c|c|c|}
\hline EMI range (thousands) & MPCE range (thousands) & $E$ range & Cost range (lacs) & $\Delta E$ & $\begin{array}{c}\text { Potential market } \\
\Delta P(\%)\end{array}$ \\
\hline $2.71-3.30$ & $2.17-2.64$ & $33.4-34.2$ & $2.67-3.25$ & 0.85 & 3.65 \\
\hline $3.30-3.9$ & $2.64-3.12$ & $34.2-34.9$ & $3.25-3.85$ & 0.73 & 1.83 \\
\hline $3.90-4.50$ & $3.12-3.60$ & $34.9-35.6$ & $3.85-4.44$ & 0.62 & 0.99 \\
\hline $4.50-5.10$ & $3.60-4.08$ & $35.6-36.1$ & $4.44-5.03$ & 0.54 & 0.58 \\
\hline $5.10-5.70$ & $4.08-4.56$ & $36.1-36.6$ & $5.03-5.62$ & 0.48 & 0.36 \\
\hline $5.70-6.30$ & $4.56-5.04$ & $36.6-37.0$ & $5.62-6.21$ & 0.43 & 0.23 \\
\hline $6.30-6.90$ & $5.04-5.52$ & $37.0-37.4$ & $6.21-6.80$ & 0.4 & 0.16 \\
\hline $6.90-7.50$ & $5.52-6.00$ & $37.4-37.8$ & $6.80-7.39$ & 0.36 & 0.11 \\
\hline $7.50-8.00$ & $6.00-6.40$ & $37.8-38.1$ & $7.39-7.89$ & 0.28 & 0.07 \\
\hline $8.00-8.50$ & $6.40-6.80$ & $38.1-38.3$ & $7.89-8.38$ & 0.26 & 0.06 \\
\hline
\end{tabular}

Table 3. EMI ranges, cost, potential market for urban India

\begin{tabular}{|c|c|c|c|c|c|}
\hline EMI range (thousands) & MPCE range (thousands) & $E$ range & Cost range (lacs) & $\Delta E$ & $\begin{array}{c}\text { Potential market } \\
\Delta P(\%)\end{array}$ \\
\hline $3.9-4.5$ & $3.14-3.6$ & $35.0-35.6$ & $3.87-4.44$ & 0.60 & 5.09 \\
\hline $4.5-5.0$ & $3.6-4.0$ & $35.6-36.0$ & $4.44-4.93$ & 0.46 & 3.27 \\
\hline $5.0-5.5$ & $4.0-4.4$ & $36.0-36.4$ & $4.93-5.42$ & 0.41 & 2.46 \\
\hline $5.5-6.0$ & $4.4-4.8$ & $36.4-36.8$ & $5.42-5.92$ & 0.38 & 1.84 \\
\hline $6.0-6.5$ & $4.8-5.2$ & $36.8-37.2$ & $5.92-6.41$ & 0.35 & 1.38 \\
\hline $6.5-7.0$ & $5.2-5.6$ & $37.2-37.5$ & $6.41-6.90$ & 0.32 & 1.10 \\
\hline $7.0-7.5$ & $5.6-6.0$ & $37.5-37.8$ & $6.90-7.39$ & 0.30 & 0.87 \\
\hline $7.5-8.0$ & $6.0-6.4$ & $37.8-38.1$ & $7.39-7.89$ & 0.28 & 0.70 \\
\hline $8.0-8.5$ & $6.4-6.8$ & $38.1-38.3$ & $7.89-8.38$ & 0.26 & 0.59 \\
\hline $8.5-9.0$ & $6.8-7.2$ & $38.3-38.6$ & $8.38-8.87$ & 0.25 & 0.47 \\
\hline
\end{tabular}

correspond to the total urban housing market on an all-India basis. Hence affordable housing for all, i.e. for total Indian population seems to be difficult at the moment as majority of the population cannot afford a house with their expenditure capacity.

\section{Market population fraction against EMI}

The minimum EMI corresponds to $25 \%$ of ALH as elaborated earlier, and are Rs 542.50 and Rs 784.50 per capita per month respectively, for rural and urban India. For a five member family, these EMIs are Rs 2712.50 and Rs 3922.50 respectively, for rural and urban India. Assuming 15 years as the repay period with $9 \%$ nominal annual interest rate ${ }^{29}$, the present cost would work out in terms of equal payment series present worth factor (EPSPWF) as

$$
\operatorname{Cost}=\left(\operatorname{EMI} *\left(\frac{(1+i)^{n}-1}{i(1+i)^{n}}\right)\right) .
$$

In the above equation, $i=0.09 / 12, n=15 \times 12=180$, and, viable minimum cost of a affordable housing unit can be calculated accordingly. This cost works out to be
Rs 2.67 lacs and Rs 3.87 lacs for rural and urban cases respectively. These values correspond to zero market population fraction, i.e. $\Delta P=0$. Similarly affordable unit costs corresponding to higher EMI range up to Rs 8500 are calculated and are given in Tables 2 and 3 for rural and urban India respectively. The MPCE values for various EMIs can be obtained as EMI $=$ MPCE $\times 5 \times 0.25$. Thus $\mathrm{MPCE}=0.8 \mathrm{EMI}$. $E$ values are calculated for MPCE values corresponding to number of EMI values in steps. The $\Delta P$, i.e. the population fraction (\%) representing potential maximum size of market, corresponding to small $\Delta E$ values for ranges of EMI above ALH and up to EMI of Rs 8500 for both rural and urban scenarios are also given in Tables 2 and 3. In Tables 2 and 3 ranges of MPCE, corresponding ranges of $E$, ranges of costs, $\Delta E$ and $\Delta P$, i.e. potential market, as percentage of population are provided. Plots of $\Delta P$ against $E$ are given in Figures 3 and 4 respectively, for rural and urban cases. Market tend to decrease with higher EMIs, but as the population is large, market in terms of absolute number that can be calculated on the basis of this analysis, may still be quite large and have the potential for exploration. The relationships for $\Delta P$ against $E$ are given in eqs (4) and (5) respectively, for all-India rural and urban populations. State wise exercise can also be carried out using the methodology presented. 


$$
\begin{aligned}
& \Delta P=0.308 E^{2}-23.11 E+433.23 . \\
& \Delta P=0.678 E^{2}-52.30 E+995.72 .
\end{aligned}
$$

\section{Construction cost and feasibility of affording house}

Affordable cost of house at the lowest level is given in Tables 2 and 3. However, feasibility of constructing a house depends upon construction cost, including structural and architectural finish cost and also cost of the land. The architectural cost per unit area depends on the levels of acceptability, where, lowest level is the one designated for EWS. Such an accommodation layout plan can be considered and are available with Central Building Research Institute (CSIR-CBRI), Roorkee, and Building Materials Promotion Council (BMPTC), New Delhi. For one bedroom apartment with a carpet area of $27.7536 \mathrm{~m}^{2}$ for EWS ${ }^{21}$. Based on the Delhi Schedule of Rates, structural cost of such an accommodation in a four storey apartment building with 16 apartments can be estimated which works out to be Rs 269,983/apartment with cast in situ, conventional techniques. The land and architectural costs will be over and above this cost. However, with the adoption of modern construction technology and indu-

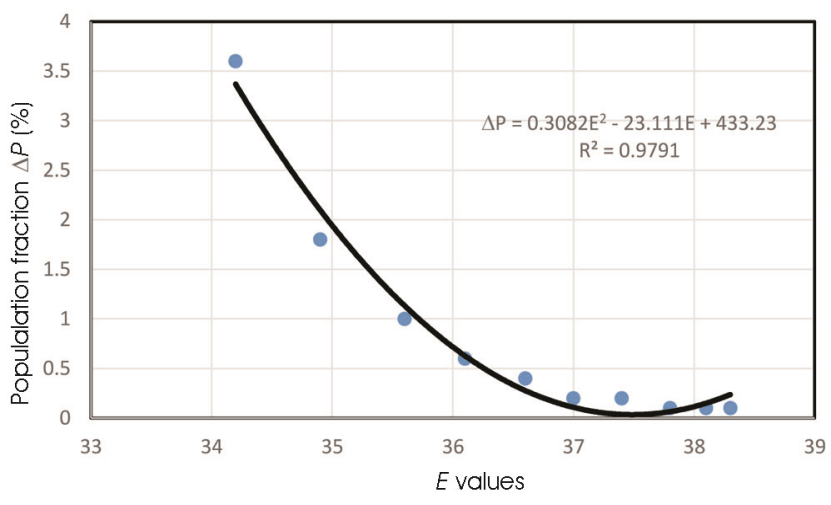

Figure 3. Potential market as $\%$ of population $\Delta P$ against $E$ (rural).

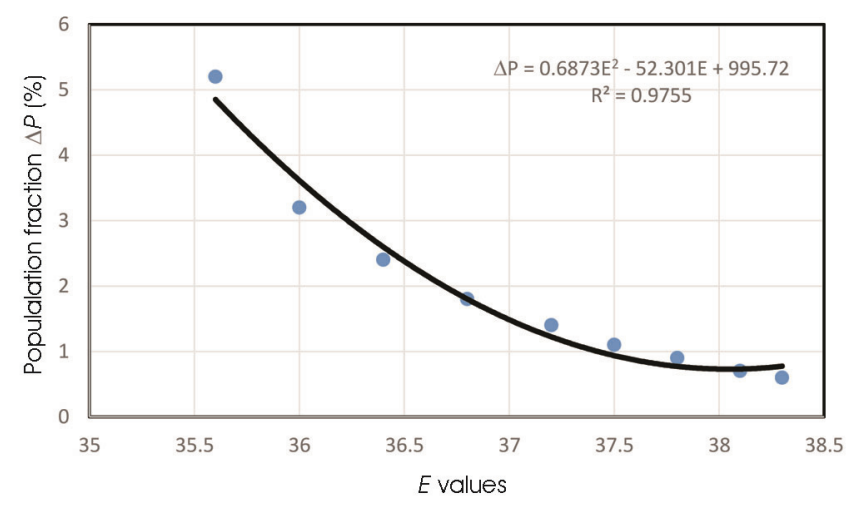

Figure 4. Potential market as $\%$ of population $\Delta P$ against $E$ (urban). strialized construction, say, precast columns, precast beams (linear system) and hollow core (planner) slab, aerated concrete (AEC) blocks, instead of burnt clay bricks, this cost can be brought down to Rs 186,240 per apartment, beyond a break-even number of buildings, which worked out to be 160 numbers $^{30}$. Thus it may be possible to utilize the market potential of around Rs 300,000400,000 , when land cost is negligible, by utilizing industrialized construction in a big way. Enhancing expenditure capacity at the lower level would increase the market significantly.

\section{Conclusion}

A relation for cumulative distribution of population against a measure of monthly per capita expenditure is presented in this paper. Through the above relation, population which can afford a house without compromising with their nutritional and other essential needs is estimated on an all-India basis. The potential market against EMI is presented and it is demonstrated that the potential of the market can be realized through adoption of industrialized construction practice.

Although the analysis and model presented is country (India) and time specific, but the methodology and form of equations presented may be equally applicable to many other countries both geographically and temporally, whenever suitable data is available.

1. National Buildings Organization (NBO), State of Housing in India - A Statistical Compendium. Ministry of Housing and Urban Poverty Alleviation, Govt of India, 2013.

2. JLL, Affordable Housing in India - Key initiatives for inclusive housing for all. Jones Lang La-Salle (JLL), India, 2016.

3. Wikipedia, Indian states ranking by families owning house, Census, 2011; https://en.wikipedia.org/wiki/Indian_states_ranking by_families_owning_house

4. NSSO, Census of India - 2011, Table H - Houses and Household amenities, NSSO Publication, 2011.

5. NSSO, Census of India 2011 Houses and household amenities and assets (PDF). National Buildings Organization (NBO): Strategy paper, Ministry of Housing and Urban Poverty Alleviation, Estimation of Urban Housing Shortage, February 2011.

6. Lee, R., Building Maintenance Management, Collins Professional and Technical Books, William Collins Sons \& Co Ltd, London, 1987.

7. Parekh, D., Report of the High Level Task Force on Affordable Housing for All. December 2008.

8. Stone, M. E., What is housing affordability? - the case for the residual income approach. Hous. Policy Debate, 2010, 17(1), 151184.

9. Kengott, G. F., The Record of a City: A Social Survey of Lowell Massachusetts, Macmillan, New York, 1912.

10. Hulchanski, D. J., The concept of housing affordability: six contemporary uses of the housing expenditure to income ratio. Housing Stud., 1995, 10(4), 471-492.

11. Houthakker, H. S., An international comparison of household expenditure patterns, commemorating the centenary of Engel's law. Econometrica, 1957, 25(4), 532-551. 


\section{GENERAL ARTICLES}

12. Stigler, G. J., The early history of empirical studies of consumer behavior. J. Polit. Econ., 1954, LXII(2), 95-113.

13. Gan, Q. and Hill, R. J., Measuring housing affordability: looking beyond the median. J. Hous. Econ., 2009, 18, 115-125.

14. Mulliner, E., Smallbone, K. and Maliene, V., An assessment of sustainable housing affordability using a multiple-criteria decision making method. Omega, 2013, 41, 270-279.

15. 12th Annual Demographia, International Housing Affordability Survey 2016, Performance Urban Planning; www.PerformanceUrbanPlanning.org

16. Kutty, N. K., A new measure of housing affordability: estimates and results. Hous. Policy Debate, 2010, 16(1), 113-142.

17. Ram, P. and Needham, B., The provision of affordable housing in India: Are commercial developers interested? Habitat Int., 2016, 55, 100-108; https://doi.org/10.1016/j.habitatint.2016.03.002.

18. Kundu, N., The case of Kolkata, India. Understanding slums: case studies for the global report on human settlements, 2003; http:// www.ucl.ac.uk/dpu-projects/Global_Report/pdfs/Kolkata.pdf

19. Jain, A. K., Housing for all optimising planning and development controls, Shelter, HUDCO-HMSI Publication, New Delhi, 2016, vol. 17(1), pp. 2-9.

20. Herda, G., Rani, S., Caleb, P. R., Gupta, R., Behal, M., Gregg, M. and Hazra, S., Sustainable social housing in India: definition, challenges and opportunities - Technical Report, Oxford Brookes University, Development Alternatives, The Energy and Resources Institute and UN-Habitat. Oxford, UK, 2017, ISBN: 978-09929299-8.

21. Garg, R. K., Study on Revision of Unit Cost under Indira Awaas Yojana (IAY) in various Geo Climatic Zones of the Country. Central Building Research Institute, Roorkee, 2010.

22. Doshi, B. V., Aranya Community Housing - Technical Summary Report, Vastu-Shilpa Foundation, Indore, 1989.
23. Bhattacharjee, B., Sustainability of concrete in Indian context. Indian Concr. J., 2010, 84(7), 45-51.

24. Vijay, P. and Bhattacharjee, B., Concrete evaluation methodology to soil blocks for sustainability. In Proceedings of UKIERI Concrete Congress. Concrete: The Global Builder, Jalandhar, 5-8 March 2019; https:/ukiericoncretecongress.com/ucc2019/files/ Proceedings/contents.html

25. Bhattacharjee, B., Influence of pore size distribution on the properties of a stabilized soil cement system. In Fourth Geo-China International Conference, Shandong, China, 25-27 July 2016, pp. 53-60.

26. NSSO, Level and Pattern of Consumer Expenditure, National Sample Statistics Office Report, 68th Round, 2011-12, Ministry of Statistics and Programme Implementation, Govt of India, 2014.

27. Planning Commission of India (PCI-GoI), Report of the Expert Committee to Review the Methodology for Estimation of Poverty in India, Planning Commission of India, 2014.

28. Mayank, H., Nanvaty, M., Chakraborty, S. B., Mitra, S. and Limaye, A., Affordable Housing in India - An inclusive approach to sheltering the bottom of the pyramid. JLL On-Point, 2012.

29. Ministry of Housing and Urban Poverty Alleviation (MHUPA), Pradhan Mantri Awas Yojana - Housing for All (Urban), Scheme Guidelines, 2015.

30. Shaik, R., Feasibility and Productivity Studies in Precast Concrete Construction. M.Tech. thesis, IIT Delhi, 2019.

Received 3 August 2020; revised accepted 3 March 2021

doi: $10.18520 / \mathrm{cs} / \mathrm{v} 120 / \mathrm{i} 10 / 1559-1566$ 